\title{
Erratum to: An overview of climate change vulnerability: a bibliometric analysis based on Web of Science database
}

\author{
Bing Wang $\cdot$ Su-Yan Pan $\cdot$ Ruo-Yu Ke $\cdot$ Ke Wang $\cdot$ Yi-Ming Wei
}

Received: 15 January 2015/Accepted: 15 January 2015/Published online: 22 January 2015

(C) Springer Science+Business Media Dordrecht 2015

\section{Erratum to: Nat Hazards (2014) 74:1649-1666 \\ DOI 10.1007/s11069-014-1260-y}

An overview of climate change vulnerability: a bibliometric analysis based on Web of Science database, Bing Wang, Su-Yan Pan, Ruo-Yu Ke, Ke Wang, Yi-Ming Wei, Nat Hazards (2014) 74:1649-1666 DOI 10.1007/s11069-014-1260-y belongs to the Special Issue: Vulnerability of Infrastructure to Natural Hazards and Climate Change in China.

The online version of the original article can be found under doi:10.1007/s11069-014-1260-y.

B. Wang · S.-Y. Pan · R.-Y. Ke · K. Wang · Y.-M. Wei ( $\)$ School of Management and Economics, Beijing Institute of Technology, Beijing 100081, China e-mail: ymwei@263.net; ymwei@deas.harvard.edu; wei@bit.edu.cn

B. Wang · S.-Y. Pan · R.-Y. Ke · K. Wang · Y.-M. Wei

Center for Energy and Environmental Policy Research, Beijing Institute of Technology,

Beijing 100081, China

B. Wang

Department of Civil Engineering, University of Ottawa, Ottawa, ON K1N6N5, Canada 